\title{
Phyto-Oestrogens and Chaste Tree Berry: A New Option in the Treatment of Menopausal Disorders
}

\author{
Vincenzo De Leo*, Valentina Cappelli, Alessandra Di Sabatino and Giuseppe Morgante \\ Molecular Medicine and Development Department, Obstetrics and Gynecology Clinic, University of Siena, Italy
}

\begin{abstract}
For a woman, menopause represents a transitional phase from a fertile to a non-fertile age, in which there is a gradual reduction in ovarian function accompanied by a gradual cessation of oestrogen production.

The clinical presentation can involve a series of disorders, including hot flushes with episodes of sweating, particularly at night, palpitations, changes in sleep-wake rhythm, irritability, anxiety and mood changes, vaginal dryness due to a process of progressive atrophy with thinning of the outer and inner labia, reduction of vascularisation and elastic fibres, and decreased sexual desire; subsequently, Many women use alternative therapies to treat hot flushes and other menopausal symptoms. The purpose of this review is to summarize current information on the efficacy and safety of phytoestrogens and the herbal medicine. Given the importance that these symptoms assume for the woman, not only for the perceived quality of life, but also for the increased risk of developing all the diseases, all the treatments adopted for menopausal women are directed primarily to resolving vasomotor disorder
\end{abstract}

Keywords: Menopause; Vasomotor symptoms; Hot flushes; Phytooestrogens; Magnolia; Chaste tree berry

\section{Introduction}

For a woman, menopause represents a transitional phase from a fertile to a non-fertile age, in which there is a gradual reduction in ovarian function accompanied by a gradual cessation of oestrogen production [1]. During this period, women are faced with irregular ovulatory or anovulatory cycles without a systematic progression from one to the other.

The mean age of onset of this phase is 40 to 50 years and it is certainly the most vulnerable period in a woman's life in that hormone deficiency causes neuroendocrine changes that constitute the pathophysiological basis of neurovegetative disorders (Figure 1).

The clinical presentation can involve a series of disorders, including hot flushes with episodes of sweating, particularly at night, palpitations, changes in sleep-wake rhythm, irritability, anxiety and mood changes, vaginal dryness due to a process of progressive atrophy with thinning of the outer and inner labia, reduction of vascularisation and elastic

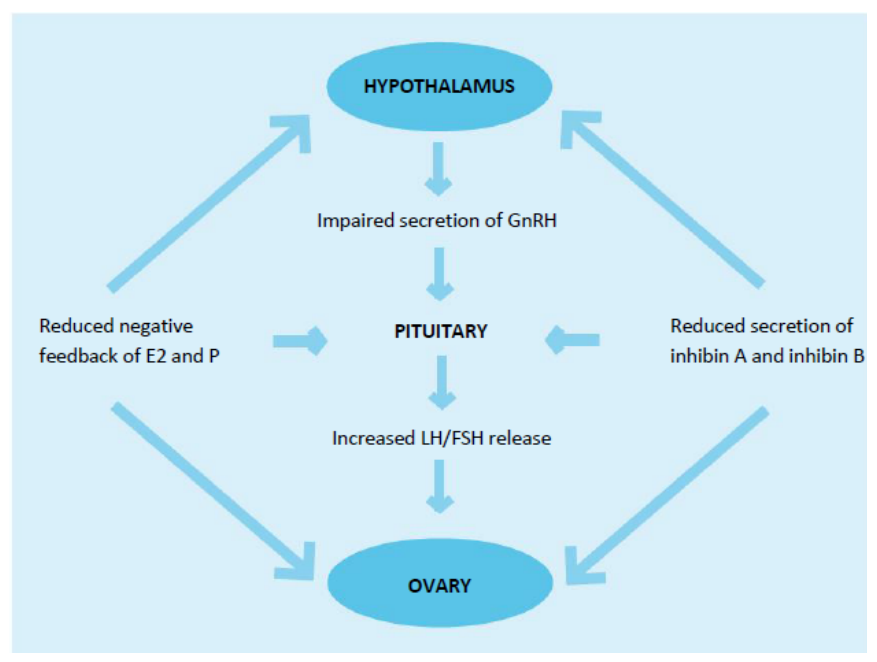

Figure 1: Main changes in the neuroendocrine axis in menopause. fibres, and decreased sexual desire; subsequently, the process of atrophy also affects the epidermis with thin, pale skin that is easily susceptible to bacterial and viral infections. A similar condition is observed in the vagina with a reduction in thickness of the mucosa, which becomes atrophic with reduced vascularisation and results in dyspareunia (Table 1) [2].

Among the most important long-term complications, attention should be drawn to the loss of minerals and consequent reduction in bone mass, which is associated with osteopenia and osteoporosis of varying degrees and dysfunction and atrophy of the genitourinary tract. With the passage of time, oestrogen deficiency in fact accelerates the process of bone demineralisation, as oestrogens promote the absorption of calcium in the intestine and the mineralisation process in bone [3].

The most common symptoms of menopause, even when taking into account all the different populations studied, are hot flushes, which affect between $65 \%$ and $86.8 \%$ of the menopausal female population, whereas night sweats affect between $65 \%$ and $82.1 \%$, insomnia between $61 \%$ and $67.8 \%$ and mood changes between $57 \%$ and $47.5 \%[4,5]$.

The symptom for which postmenopausal women most frequently visit their doctor for relief is the occurrence of hot flushes [6]. This symptom is present in more than $80 \%$ of women entering into physiological menopause, while it affects more than $90 \%$ of women who have undergone surgical removal of the ovaries. Menopausal symptoms must not be regarded simply as disorders associated with deterioration in the quality of the life, but also as a risk factor for the development of osteoporosis, as well as cardiovascular diseases and brain deterioration $[7,8]$.

*Corresponding author: Prof Vincenzo De Leo, Molecular Medicine and Development Department, University of Siena, Italy, Tel: +390577233465 ; Fax: +390577233454; E-mail: vincenzo.deleo@unisi.it

Received February 26, 2014; Accepted August 14, 2014; Published August 18, 2014

Citation: Leo VD, Cappelli V, Sabatino AD, Morgante G (2014) Phyto-Oestrogens and Chaste Tree Berry: A New Option in the Treatment of Menopausal Disorders. J Women's Health Care 3: 182. doi:10.4172/2167-0420.1000182

Copyright: ( 2014 Leo VD, et al. This is an open-access article distributed under the terms of the Creative Commons Attribution License, which permits unrestricted use, distribution, and reproduction in any medium, provided the original author and source are credited. 


\begin{tabular}{|c|c|c|}
\hline $\begin{array}{l}\text { Short-term } \\
\text { symptoms }\end{array}$ & $\begin{array}{l}\text { Medium-term } \\
\text { symptoms }\end{array}$ & $\begin{array}{l}\text { Long-term } \\
\text { symptoms }\end{array}$ \\
\hline $\begin{array}{l}\text { - Menstrual irregularity } \\
\text { - Hot flushes } \\
\text { - Sweating } \\
\quad \text { (including at night) } \\
\text { - Insomnia } \\
\text { - Anxiety } \\
\text { - Depression } \\
\text { - Asthenia } \\
\text { - Irritability }\end{array}$ & $\begin{array}{l}\text { - Urogenital disorders } \\
\text { o Vaginal dryness } \\
\text { o Dyspareunia } \\
\text { o Urinary incontinence } \\
\text { - Cutaneous and mucosal atrophy } \\
\text { o Cutaneous hypoelasticity } \\
\text { (increased wrinkles) } \\
\text { o Atrophy of the oral mucosa } \\
\text { o Eye symptoms } \\
\text { - Obesity }\end{array}$ & $\begin{array}{l}\text { - Osteoporosis } \\
\text { - Cardiovascolar } \\
\text { disorders } \\
\text { - Atherosclerosis } \\
\text { - Alzheimer's } \\
\text { disease }\end{array}$ \\
\hline
\end{tabular}

Table 1: Schematic representation of the main short-term, medium-term and longterm symptoms of menopausal women.

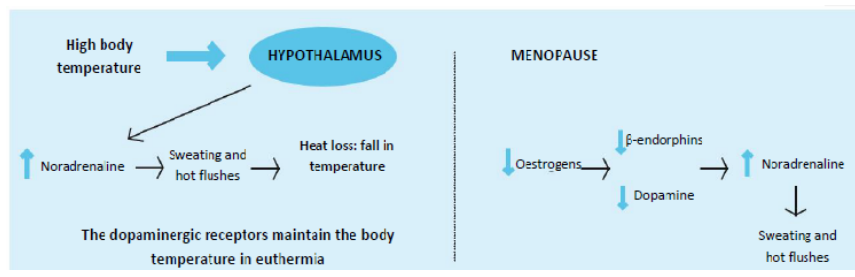

Figure 2: Heat control system during fertile life and changes in the menopausal woman.

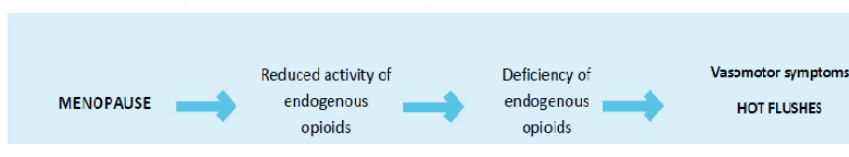

Figure 3: Mechanism of development of hot flushes in menopause.

A review from 2009 on this subject shows that more severe hot flushes can be correlated with rapid bone loss and the subsequent development of osteoporosis within a short period of time [9]; they are also related to a weaker verbal memory [10] and reduced levels of plasma antioxidants, but also to an increased cardiovascular stress response and to changes in blood pressure.

The vasomotor symptoms are also correlated with a significant increase in the risk of coronary heart disease, which does not appear to be entirely explicable by other risk factors for coronary heart disease [11].

Given the importance that these symptoms assume for the woman, not only for the perceived quality of life, but also for the increased risk of developing all the diseases listed above, all the treatments adopted for menopausal women are directed primarily to resolving vasomotor disorders.

\section{Changes in Thermoregulation During Menopause}

The hypothalamus is the CNS structure that, as well as various other functions, is specifically devoted to maintaining body temperature and the sleep-wake rhythm, as well as to maintaining water and salt balance and regulating food intake.

In the hypothalamus, the anterior and preoptic nuclei are responsible for cooling, whereas the posterior nucleus is devoted to heating; these centres possess cells that are able to respond to variations in body temperature, which is recorded from the temperature of the blood that reaches the encephalon. When the temperature is higher than physiological levels, the posterior nucleus releases noradrenaline, which in turn stimulates the nuclei in the anterior hypothalamus, culminating in a response that causes an increase in sweating and peripheral vasodilatation and thus returning the system to a state of equilibrium. It is specifically the increase in noradrenaline which results in sweating and hot flushes in menopausal women with the aim of reducing raised body temperature [12]

Dopamine also plays an important role in thermoregulation in that it too is devoted to maintaining a state of euthermia via the $\mathrm{D}_{2}$ receptors. As has long been known, bromocriptine, a dopamine agonist, is able to increase the activity of the hypothalamic endogenous opioid system ( $\beta$-endorphins) on the mechanisms regulating body temperature in menopause [13]. In fact, $\beta$-endorphins are also involved in thermoregulatory homeostasis and inhibit the noradrenergic neurons below the threshold at which heat loss is activated.

During fertile life, oestrogens play an important role in modifying the synthesis, release and metabolism of many neurotransmitters, including dopamine and melatonin, which are responsible for modulating the hypothalamic and limbic systems.

It is therefore clear that the decrease in oestrogen levels from the perimenopausal period until overt menopause is accompanied by changes in function of these systems, which is of particular relevance to thermoregulation and vasomotor stability.

The resultant outcome is connected with menopausal symptoms. The menopausal changes therefore induce a temporary imbalance of thermoregulation in the hypothalamus, modulating the homeostasis of the body temperature to values below physiological levels, which are then achieved by the dispersal of heat by means of vasodilatation and profuse sweating.

Postmenopausally, the decrease in oestrogens reduces the inhibitory activity of $\beta$-endorphins on noradrenaline and causes an increase in activity of the noradrenergic system but also a reduction of the dopaminergic system, which is significantly less active than in premenopausal women (Figures 2 and 3) [7,8].

All these mechanisms explain the positive effect of hormone therapy, resulting in stimulation of the $\mathrm{D}_{2}$ dopaminergic receptors and the subsequent attenuation of the menopausal symptoms associated with hot flushes and sweating, with a consequent improvement also in the psychological correlations and a decrease in the risk factors for osteoporotic and cardiovascular diseases.

Melatonin levels and the time during which these levels remain high during the night also differ during the various phases of life, with a significant decrease with advancing age; this explains why sleep is often disturbed and is of poorer quality in the elderly [14].

Perimenopausally, it has been shown that the reduction in melatonin secretion precedes the increase in FSH in menopause.

Moreover, the instability of the ovarian hormones and their fluctuation during the perimenopausal period destabilises the physiological circadian rhythm and the decrease in oestrogens can also contribute significantly to changes in mood and physiological wellbeing.

A genuine problem that frequently occurs when a woman asks for relief of the vasomotor disorders that afflict her is represented by the fact that, as is now well known, the traditional Hormone Replacement Therapy (HRT) is accepted and used by only a small percentage of women (about 8\%), as the literature reports that there is a state of fear of an increased risk of breast cancer that in fact causes doctors not to prescribe such drugs, although very often it is the women themselves who refuse to use them. 


\begin{tabular}{|c|c|}
\hline \multicolumn{2}{|c|}{ HORMONE REPLACEMENT THERAPY } \\
\hline Positive effects & Risks \\
\hline Reduction of menopausal symptoms & Venous thromboembolism \\
\hline Prevention of osteoporosis & Cardiovascular risk \\
\hline Increased trophism of the urogenital tract & Risk of breast $\mathrm{Ca}$ \\
\hline
\end{tabular}

Table 2: Schematic representation of the main positive effects and possible risk factors of the use of hormone replacement therapy (HRT).

\begin{tabular}{|c|c|c|}
\hline ISOFLAVONES & COUMESTANS & LIGNANS \\
\hline $\begin{array}{l}\text { Genistein } \\
\text { - Soya and derivatives } \\
\text { Daidzein } \\
\text { - Legumes } \\
\text { Glycitein } \\
\text { - Clover } \\
\text { Biochanin A } \\
\text { - Whole grains } \\
\text { Formononetin }\end{array}$ & $\begin{array}{l}\text { Coumestrol } \\
\text { - Beans, soya sprouts } \\
\text { 4-Methoxycoumestrol } \\
\text { - Cloves, soya sprouts, } \\
\text { red clover, sunflower } \\
\text { seeds }\end{array}$ & $\begin{array}{l}\text { Enterodiol } \\
\text { - Linseed and sesame } \\
\text { seeds } \\
\text { Enterolactone } \\
\text { - Soya, hops, fruit and } \\
\text { vegetables, cereals }\end{array}$ \\
\hline
\end{tabular}

Table 3: Subdivision of classes and subclasses of phyto-oestrogens and principal dietary sources.

\section{Hormone Replacement Therapy (HRT)}

A reasoned choice of the therapeutic protocol in terms of preparation type, dosage, therapeutic regimen and route of administration is essential for the rational use of HRT. As confirmed by the results of the WHI study, different therapeutic strategies must be chosen with an individualised risk-benefit assessment. In recent years, following a few clinical studies that had aroused considerable fear, the therapeutic approaches to postmenopausal women have been reviewed [15]. Additionally, new treatment protocols have been identified with low oestrogen doses that are effective in controlling postmenopausal symptoms and reducing the incidence of side effects and potential risks associated with the duration of treatment (Table 2).

The reduction in the dose of oestrogens to be administered does not preclude the fact that all women must undergo tests before starting treatment. Women who take hormone therapy should undergo a clinical follow-up at least once a year, including a gynaecological visit, updating of the medical history, laboratory and instrumental tests and a lifestyle assessment. Mammography must be performed, preferably within 12 months of the start of treatment [16]; increased breast density can be attributed predominantly to the effects of the progestin component of HRT $[17,18]$.

The woman must be examined from an endocrine and metabolic standpoint, the type of oestrogen and possibly the most suitable type of progestin must be chosen, as well as the best route of administration and the combination modality best suited to the individual [15].

The main aim of hormone replacement therapy is to improve the quality of life of patients in spontaneous or surgical postmenopause who are experiencing menopausal symptoms [2]: hot flushes [6], nocturnal sweating, vaginal atrophy, dyspareunia, neurovegetative problems, osteoporosis [3] or a familial history of osteoporosis, with high levels of total cholesterol and low levels of HDL-cholesterol, and with a family history of cardiovascular diseases [19-21]. HRT should be considered in the absence of contraindications and after discussing the potential risks and benefits with the woman [22]. HRT is contraindicated in women with a positive history of breast cancer $[23,24]$ or endometrial cancer [25], in women with thromboembolic episodes [26] during pregnancy or in those taking oral contraceptives, with any current liver diseases or, at all events, with impaired liver function.

\section{Phyto-oestrogens}

In recent times, the pharmaceutical market has been enriched by numerous products known as food supplements based predominantly on phyto-oestrogens, or plant oestrogens, derived from soya and combined with vitamins and other plant substances, which have made them greatly appreciated by women, both for the relief of disorders of the perimenopausal and overt menopausal period, and during the fertile life. It is the gynaecologist's task to identify the right products to recommend to women based on the quantities and quality of substances present.

Phyto-oestrogens are compounds that are present in many plants with a very similar action to mammalian oestrogens.

However, some clarifications are needed about phyto-oestrogens, since they do not all have the same therapeutic efficacy.

These products exert a gentle and balanced oestrogenic action due to the active ingredients they contain; more precisely, by virtue of their particular chemical structure, they are able to bind to oestrogen receptors and thus exert biological activity of an oestrogenic or antioestrogenic nature. The diversification of this effect depends on their concentration, that of the oestrogens produced by the body and on certain individual characteristics (tissue concentration of receptors and enzymes involved in the metabolism of these hormones).

Phyto-oestrogens are commonly divided into three main classes: isoflavones, coumestans and lignans (a fourth category that of lactones is of little therapeutic value) (Table 3 ). They are ubiquitous in the plant world (present in at least 300 varieties of plants, few of which are edible). In terms of food sources, mention may be made of soya, legumes and, albeit in small quantities, many types of fruits, vegetables and wholegrain.

Soya, its derivatives (flour, soya milk and tofu) and red clover represent the main commercial sources of phyto-oestrogens.

Soya isoflavones in particular have a higher oestrogenic activity than other phyto-oestrogens. They bind to the oestrogen receptor, albeit with lesser affinity, forming a receptor complex that functions in a similar way. Many of the health-giving properties of isoflavones are attributable to the weak oestrogenic action of genistein and daidzein, the two most important isoflavones, and their interaction with the oestrogen receptors that are distributed throughout the body. Genistein has a seven-fold greater oestrogenic activity than daidzein.

As well as the biological significance, the indications for phytooestrogens are also now well known; these substances have a known antioxidant and oestrogenic activity (they reduce disorders due to both a deficiency and an excess of oestrogens).

Recent studies have shown the progressive reduction in hot flushes and sweating following treatment with phyto-oestrogens. Doses of $45-$ $90 \mathrm{mg}$ of soya isoflavones, equal to about 2-3 soya-based meals a day, should be used to provide protection against hot flushes.

It has emerged from these studies that soya isoflavones do not stimulate endometrial growth and therefore they do not increase the risk of endometrial or uterine tumours [27]. Other studies have shown that the continuous administration of phyto-oestrogens derived from soya isoflavones exerts a protective action against cardiovascular diseases and postmenopausal osteoporosis.

It has been shown that phyto-oestrogens exert a protective action on blood vessels and against heart diseases. Following constant and 
sustained intake, they can in fact reduce levels of triglycerides and lowdensity lipoproteins (LDL or bad cholesterol) and increase levels of high density cholesterol (HDL or good cholesterol) [28].

Isoflavone supplements allow a better knowledge of the dosage than the consumption of soya-rich foods, which is reflected in greater efficacy. The results can be appreciated more clearly after the second week of intake. In addition, these products do not cause any side effects.

The commercially available soya isoflavone-based supplements are not all equal. As well as high-quality products, unregulated products and/or those of a low technological level can be found. Many commercialised products refer to generic extracts of soya or isoflavones without specifying the type of isoflavones they contain and exhibit a different genistein/daidzein ratio from that found in nature; in addition, some contain less active isoflavones, such as glycitein.

Following the example of oral therapy, some soya isoflavone-based topical formulations have been marketed with the aim of treating and preventing postmenopausal vulvovaginal symptoms. The availability of products containing an adequate dose of soya isoflavones has shown to be effective, not only in curing vulvovaginal symptoms by more continuous administration, but also in preventing their development by periodic administration, in alternate 3 -month cycles, which is met with greater approval by the women.

Among other effects, oestrogens also possess an antioxidant activity, thus inhibiting the formation of free radicals. Phytoestrogens have also been shown to exert marked antioxidant, anti-inflammatory and antihypertensive activity. Therefore, food supplements, in particular multivitamins, represent a valid alternative to hormone replacement therapy in menopausal woman.

Supplements that contain vitamin D and calcium as well as phytooestrogens are indicated in the prevention of osteoporosis as a result of their joint action of increasing intestinal absorption of calcium and increasing its availability in bone, thus making the latter less fragile.

Combinations of phyto-oestrogens and other substances produce an improvement in menopausal symptoms.

Over the years, there have been numerous combinations of phytooestrogens and various other vitamin or beneficial substances, but recently pharmaceutical companies have particularly focussed on some substances that can help relieve the disorders suffered by women in the peri- and postmenopausal period as much as possible. Various substances have been studied and, of these, some deserve particular mention, such as magnolia, lactobacilli, vitamin D and calcium, which act specifically on the disorders that women complain of most often [4]. Vitamin D and calcium are very well known for their activity on bone and therefore in the prevention of osteopenia and, in time, osteoporosis, and their beneficial properties are now confirmed.

In terms of the beneficial activity of the combination of phytooestrogens and probiotic lactic ferments, mention may be made of Lactobacillus sporogenes (Bacillus coagulans), which reaches the distal part of the small and large intestine in live form, where it germinates and produces enzymes, vitamins and lactic acid, thus creating favourable conditions for the absorption of calcium, magnesium, phosphorus, iron and copper, but also trace elements and vitamins. In combination with phyto-oestrogens, it is useful by virtue of its capacity for producing glycosidase, an enzyme that releases the main active ingredients of soya isoflavones by cleaving their glycoside bond; lactobacilli therefore improve the activity of phyto-oestrogens by stabilising the intestinal bacterial flora and allowing the constant absorption of the active ingredients.

A 2011 study shows that bioavailability varies with single doses of two oral formulations of isoflavones (genistein) with and without lactobacilli, with a significant increase in the peak plasma concentration compared with the same dose of isoflavones without lactobacilli.

A symptom that is often associated with hot flushes in a large number of women is a poorly tolerated state of anxiety that often causes a profound state of psychological prostration; this condition is also often correlated with a sense of constant tiredness and asthenia, with a deterioration in the quality of rest and with a decrease in actual hours of sleep.

In terms of this important symptom, the marked anti-anxiogenic properties of magnolia extract are well known [29]. Magnolia extract exerts a calming and comforting effect, without however causing daytime drowsiness, and does not have the side effects that characterised prescription anxiolytics. The main active ingredients are magnolol and honokiol, which have modulating capacities on the GABAA receptors of the cerebral limbic system, which is the centre devoted to emotions and feelings. This explains how this substance can have beneficial effects on changes in the sleep-wake rhythm through a calming, muscle-relaxing and balance-restoring action.

Magnolia extract also reduces blood cortisol levels, which are increased in stress states; therefore, this substance also exhibits adaptive activity in situations of severe psychological and physical stress [30].

Recent studies comparing magnolia extract with diazepam in women who have stress-related anxiety and are overweight have shown its equivalent efficacy to that of the drug [31,32].

Because postmenopause is a condition in which weight gain represents a clinical condition that affects many women and in most cases is associated with anxiety, this mechanism is converted into a greater sensation of hunger with a preference for carbohydrates and simple sugars, causing a sort of vicious cycle.

There have been no reports of relevant side effects for any of these ingredients and there is optimal compliance on the part of the women mainly because they know they are taking natural products that do not negatively interfere with their own genital tract and with the risk of developing breast cancer.

\section{Chaste tree berry}

Particular mention should be made of chaste tree berry, which is characterised by a few specific beneficial properties for postmenopausal women.

Chaste tree berry (Vitex Agnus-castus) is a phytocomplex containing glycosides, flavonoids, terpenes and alkaloids, and its main active ingredient is agnuside; it has always been known as a product that can resolve premenstrual syndrome problems in women of fertile age and recently its usefulness has also been observed in menopause, particularly in respect of vasomotor symptoms [5]. These data have suggested that there may be an analogy between this syndrome and menopausal symptoms. The mechanism of action of chaste tree berry involves an increase in hypothalamic dopaminergic tone; it expresses a binding affinity with oestrogen $\alpha(E R \alpha)$ and $\beta$ (ER $\beta)$ receptors and stimulates m-RNA expression by the progesterone receptor (PR expression) and that of pS2 (presenelin-2), another oestrogen-inducible gene (Figure 4) [5,33]. Dopamine is the main neurotransmitter that 


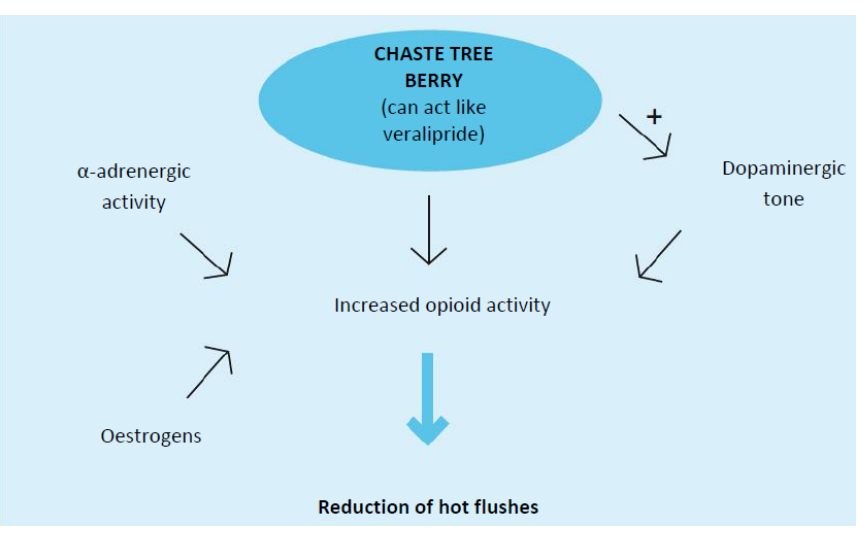

Figure 4: Mechanism of action of chaste tree berry on hot flushes.

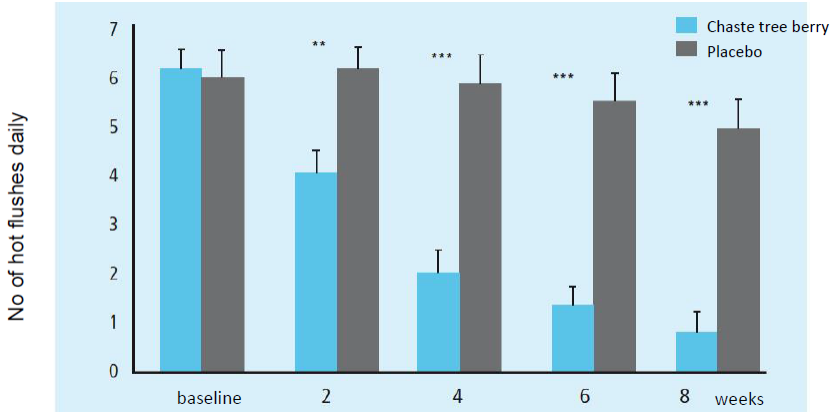

Figure 5: Reduction in the daily frequency of hot flushes after 2, 4, 6 and 8 weeks of treatment with chaste tree berry in menopausal women compared with women treated with placebo only.

$p$ values $<0.05$ were considered significant; ${ }^{* *}=p<0.01$ and ${ }^{* * *}=p<0.001$

controls the secretion of prolactin (Prl) by way of inhibition. There are clear data to show how it corrects the deficiency of progesterone in the corpus luteum during fertile life, by its action as a dopamine agonist, and how it causes an improvement in menopausal symptoms by reducing Prl levels.

in recent years, it has also emerged that, through its dopaminergic action, chaste tree berry is also capable of engendering beneficial effects by improving the emotional symptoms typical of the menopause, because a decrease in dopaminergic tone is correlated with psychological symptoms [34].

A 2011 study has shown how the daily incidence of hot flushes after 8 weeks of treatment is significantly decreased in women taking chaste tree berry compared with a group taking placebo (Figure 5) [35]; in addition, Kupperman's index in the group treated with chaste tree berry showed a statistically significant difference in terms of the severity of hot flushes, night-time sweating, insomnia, anxiety, depression, asthenia and headache compared with the control group. However, there are few studies to date that focus on the possible activity of chaste tree berry on sexual desire in menopausal women, although data available to us regarding the dopaminergic and opioid action also suggest the possibility of a topical formulation for treating dyspareunia in these women [36].

This evidence suggests that the combination of phyto-oestrogens and chaste tree berry can convincingly resolve the vasomotor and psychological symptoms typical of peri- and postmenopausal women.
On the basis of these considerations, the potential availability of a complete product consisting of phyto-oestrogens, chaste tree berry and magnolia extract can be particularly useful, not only in resolving vasomotor symptoms, but also in acting on the neuroendocrine component that is the main cause of anxiety and certain neurovegetative symptoms, such as sweating and night-time awakenings

\section{Correlations Between Premenstrual Syndrome and Vasomotor Symptoms in Menopause}

There is a correlation between premenstrual syndrome and vasomotor symptoms, i.e. women who have suffered from premenstrual syndrome during their fertile life show more severe vasomotor symptoms in the postmenopausal period.

One of the factors predominantly involved in the aetiopathogenesis of both conditions is certainly the change in the dopaminergic and serotoninergic systems, so that the administration of dopaminergic drugs, such as bromocriptine and/or cabergoline, can improve both sets of symptoms by normalising the dopaminergic and serotoninergic systems.

The success of administration of chaste tree berry in women with premenstrual syndrome is due to the restoration of a normal dopaminergic tone. Postmenopausally, the combination of phytooestrogens and chaste tree berry produces a more beneficial effect on dopaminergic tone with a more significant reduction in the incidence of vasomotor symptoms and, particularly, hot flushes.

The simultaneous presence of magnolia also encourages more physiological sleep with fewer night-time awakenings.

\section{Conclusions}

For all of the above reasons, soya isoflavones, which, in the light of numerous clinical studies and according to reports from women, appear to act by improving vasomotor symptoms, represent a valid alternative to HRT. The properties of isoflavones are not limited to vasomotor symptoms alone, but they also have positive effects on bone mass in that oestrogen $\beta$ receptors, with which soya phyto-oestrogens have a greater affinity, are strongly expressed in bone.

In addition, isoflavones exert an antioxidant action, reducing free radicals, and have an inhibitory effect on the enzyme aromatase that converts androgens to oestrogens in adipose tissue and increases the risk of endometrial and breast cancer. Products used postmenopausally not only contain phyto-oestrogens, but are often combined with calcium, vitamin D and other components, as is the case with the latest preparation in which magnolia and in particular chaste tree berry contribute significantly to improving vasomotor and neurovegetative symptoms.

\section{References}

1. Al-Anazi AF, Qureshi VF, Javaid K, Qureshi S (2011) Preventive effects of phytoestrogens against postmenopausal osteoporosis as compared to the available therapeutic choices: An overview. J Nat Sci Biol Med 2: 154-163.

2. National Institutes of Health (2005) National Institutes of Health State-ofthe-Science Conference statement: management of menopause-related symptoms. Ann Intern Med 142: 1003-1013.

3. North American Menopause Society (2006) Management of osteoporosis in postmenopausal women: 2006 position statement of The North American Menopause Society. Menopause 13: 340-367.

4. Mucci M, Carraro C, Mancino P, Monti M, Papadia LS, et al. (2006) Soy isoflavones, lactobacilli, Magnolia bark extract, vitamin D3 and calcium. Controlled clinical study in menopause. Minerva Ginecol 58: 323-334. 
5. Lucks BC, Sørensen J, Veal L (2002) Vitexagnus-castus essential oil and menopausal balance: a self-care survey. Complement Ther Nurs Midwifery 8 : $148-154$

6. Ohayon MM (2006) Severe hot flashes are associated with chronic insomnia. Arch Intern Med 166: 1262-1268.

7. Ettinger B, Pressman A, Silver $P$ (1999) Effect of age on reasons for initiation and discontinuation of hormone replacement therapy. Menopause 6: 282-289.

8. Kronenberg F (1990) Hot flashes: epidemiology and physiology. Ann N Y Acad Sci 592: 52-86

9. Gambacciani M, Pepe A (2009) Vasomotor symptoms and cardiovascular risk Climacteric 12 Suppl 1: 32-35

10. Maki PM, Drogos LL, Rubin LH, Banuvar S, Shulman LP, et al. (2008) Objective hot flashes are negatively related to verbal memory performance in midlife women. Menopause 15: 848-856.

11. Lisabeth L, Bushnell C (2012) Stroke risk in women: the role of menopause and hormone therapy. Lancet Neurol 11: 82-91.

12. Rapkin AJ (2007) Vasomotor symptoms in menopause: physiologic condition and central nervous system approaches to treatment. Am J Obstet Gynecol 196: $97-106$

13. Cagnacci A, Melis GB, Soldani R, Gambacciani M, Paoletti AM, et al. (1989) Regulation of body temperature in postmenopausal women: interactions between bromocriptine and the endogenous opioid system. Life Sci 44: 13951402.

14. Blaicher W, Speck E, Imhof MH, Gruber DM, Schneeberger C, et al. (2000) Melatonin in postmenopausal females. Arch Gynecol Obstet 263: 116-118.

15. AACE Menopause Guidelines Revision Task Force (2011) American Association of clinical Endocrinologists medical guidelines for clinical practice for the diagnosis and treatment of menopause. Endocr Pract. 12: 315-337.

16. Glass AG, Lacey JV Jr, Carreon JD, Hoover RN (2007) Breast cance incidence, 1980-2006: combined roles of menopausal hormone therapy, screening mammography, and estrogen receptor status. J Natl Cancer Inst 99 $1152-1161$

17. Grady D, Vittinghoff E, Lin F, Hanes V, Ensrud K, et al. (2007) Effect of ultralow-dose transdermal estradiol on breast density in postmenopausal women. Menopause 14: 391-396

18. Stefanick ML, Anderson GL, Margolis KL, Hendrix SL, Rodabough RJ, et al. (2006) Effects of conjugated equine estrogens on breast cancer and mammography screening in postmenopausal women with hysterectomy. JAMA 295: $1647-1657$

19. Alonso de Leciñana M1, Egido JA, Fernández C, Martínez-Vila E, Santos S, et al. (2007) Risk of ischemic stroke and lifetime estrogen exposure. Neurology 68: $33-38$.

20. Lemaitre RN, Weiss NS, Smith NL, Psaty BM, Lumley T, et al. (2006) Esterified estrogen and conjugated equine estrogen and the risk of incident myocardial infarction and stroke. Arch Intern Med 166: 399-404.

21. Manson JE, Allison MA, Rossouw JE, Carr JJ, Langer RD, et al. (2007) Estrogen therapy and coronary-artery calcification. N Engl J Med 356: 2591-2602.

22. Barnabei VM, Cochrane BB, Aragaki AK, Nygaard I, Williams RS, et al. (2005) Menopausal symptoms and treatment-related effects of estrogen and progestin in the Women's Health Initiative. Obstet Gynecol 105: 1063-1073.
23. Bernstein $L$ (2006) The risk of breast, endometrial and ovarian cancer in users of hormonal preparations. Basic Clin Pharmacol Toxicol 98: 288-296.

24. Chlebowski RT, Anderson G, Pettinger M, Lane D, Langer RD, et al (2008) Estrogen plus progestin and breast cancer detection by means of mammography and breast biopsy. Arch Intern Med 168: 370-377.

25. American College of Obstetricians and Gynecologists Committee on Gynecologic Practice (2006) ACOG committee opinion. No. 337: Noncontraceptive uses of the levonorgestrel intrauterine system. Obstet Gynecol 107: 1479-1482.

26. Canonico M, Oger E, Plu-Bureau G, Conard J, Meyer G, et al. (2007) Hormone therapy and venous thromboembolism among postmenopausal women: impact of the route of estrogen administration and progestogens: the ESTHER study. Circulation 115: 840-845

27. Palacios S, Pornel B, Vázquez F, Aubert L, Chantre P, et al. (2010) Longterm endometrial and breast safety of a specific, standardized soy extract. Climacteric 13: 368-375.

28. Baum JA, Teng H, Erdman JW Jr, Weigel RM, Klein BP, et al. (1998) Long-term intake of soy protein improves blood lipid profiles and increases mononuclea cell low-density-lipoprotein receptor messenger RNA in hypercholesterolemic, postmenopausal women. Am J Clin Nutr 68: 545-551.

29. Alexeev M, Grosenbaugh DK, Mott DD, Fisher JL (2012) The natural products magnolol and honokiol are positive allosteric modulators of both synaptic and extra-synaptic GABA(A) receptors. Neuropharmacology 62: 2507-2514.

30. Kalman DS, Feldman S, Feldman R, Schwartz HI, Krieger DR, et al. (2008) Effect of a proprietary Magnolia and Phellodendron extract on stress levels in healthy women: a pilot, double-blind, placebo-controlled clinical trial. Nutr J. 21:7-11.

31. Seo JJ, Lee SH, Lee YS, Kwon BM, Ma Y, et al. (2007) Anxiolytic-like effects of obovatol isolated from Magnolia obovata: involvement of GABA/benzodiazepine receptors complex. Prog Neuropsychopharmacol Biol Psychiatry 31: 13631369.

32. Benvenuti C, Setnikar I (2011) Effect of Lactobacillus sporogenes on ora isoflavones bioavailability: single dose pharmacokinetic study in menopausal women. Arzneimittelforschung 61: 605-609.

33. Liu J, Burdette JE, Xu H, Gu C, van Breemen RB, et al. (2001) Evaluation of estrogenic activity of plant extracts for the potential treatment of menopausa symptoms. J Agric Food Chem 49: 2472-2479.

34. van Die MD, Burger HG, Teede HJ, Bone KM (2009) Vitex agnus-castus (Chaste-Tree/Berry) in the treatment of menopause-related complaints. J Altern Complement Med 15: 853-862.

35. Abbaspoor Z, Azam Hajikhani NA, Afsharl P (2011) Effects of Vitex-agnuscastus on menopausal early symptoms in postmenopausal women: a randomized double-blind, placebo-controlled study. Brtt $\mathrm{J}$ Med \& Med Res 1:132-140.

36. Mazaro-Costa R, Andersen ML, Hachul H, Tufik S (2010) Medicinal plants as alternative treatments for female sexual dysfunction: utopian vision or possible treatment in climacteric women? J Sex Med 7: 3695-3714. 